\title{
CONFLITOS SOCIOECONÔMICOS RELACIONADOS À PESCA DA COMUNIDADE DO FAROL DE SANTA MARTA - SC/ BRASIL
}

\section{SOCIOECONOMIC CONFLICTS RELATED TO THE FISHING OF THE SANTA MARTA LIGHTHOUSE COMMUNITY - SC/BRAZIL}

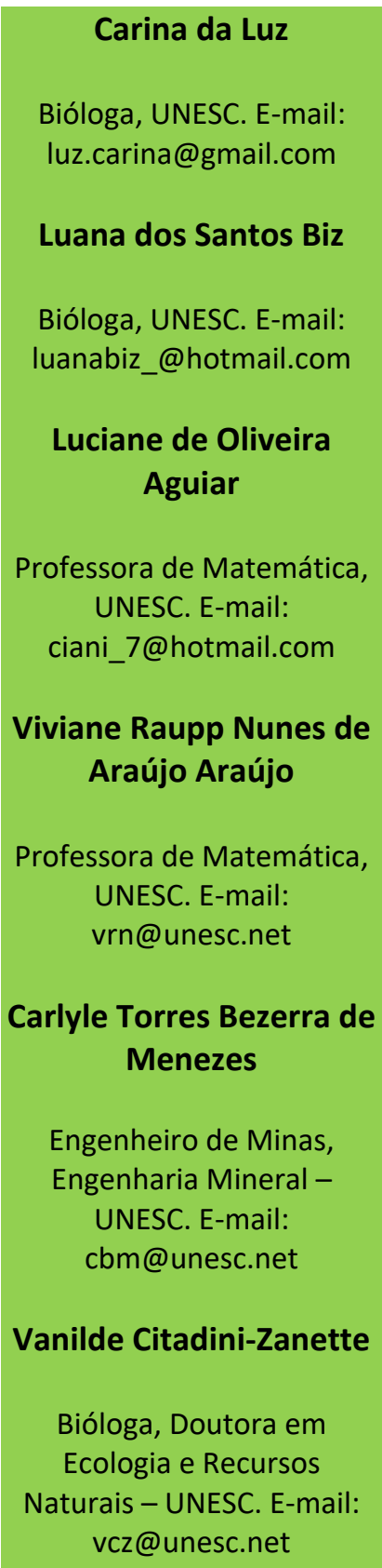

\section{RESUMO}

O presente artigo é resultado de uma prática de campo na comunidade de pescadores do Farol de Santa Marta/SC, como parte integrante da disciplina de Etnobiologia, do Programa de Pós-graduação em Ciências Ambientais (PPGCA) da Universidade do Extremo Sul Catarinense (UNESC). Teve o intuito de relatar os aspectos peculiares do modo de organização da comunidade e dar ênfase nas atividades relacionadas à pesca artesanal e ao turismo comunitário. O texto está divido em três partes, todas diretamente relacionadas à organização e desenvolvimento da região. A primeira teve o objetivo de caracterizar a comunidade em seu processo histórico de origem, a segunda traz a discussão da pesca artesanal e seus conflitos socioeconômicos e, por fim, a terceira aborda os principais conflitos e fatores que afetam a estabilidade dos sistemas pesqueiros.

Palavras-chave: Farol de Santa Marta. Pesca artesanal. Turismo Comunitário.

\section{ABSTRACT}

This article is the result of a visit to the fishermen community of the Santa Marta Lighthouse/SC, as an integral part of the Ethnobiology discipline, in the Graduate Program in Environmental Sciences of the University of Extremo Sul Catarinense - UNESC. It aims to report on the peculiar aspects of the community organization and to emphasize the activities related to artisanal fishing and community tourism. The text is divided in three parts all directly related to the organization and development of the region. The first one aims to characterize the community in its historical process of origin, the second brings the discussion of artisanal fishing and its socioeconomic conflicts and finally the results and discussions: main conflicts factors that affect the stability of the fishing systems.

Keywords: Lighthouse of Santa Marta; Artisanal fishing. Community tourism. 


\section{INTRODUÇÃO}

Este trabalho é o resultado de uma saída a campo realizada como parte integrante da disciplina de Etnobiologia, no Programa de Pós-graduação em Ciências Ambientais (PPGCA) da Universidade do Extremo Sul Catarinense (UNESC), na comunidade de pescadores do Farol de Santa Marta, município de Laguna, Santa Catarina.

Fazendo uma análise das principais atividades econômicas realizadas no litoral de Santa Catarina, é possível observar que a exploração de recursos marinhos apresenta-se como importante atividade tanto socioeconômica quanto cultural. Segundo Branco (1999), essa atividade foi uma dentre os legados da cultura açoriana que contribuiu de maneira expressiva para o desenvolvimento da pesca artesanal e industrial no litoral catarinense.

A partir de 1950, com o aumento das embarcações movidas por motor e a óleo, foi possível observar que a pesca artesanal vem sendo afetada com a pressão da pesca industrial em toda a costa. Atualmente, o que se observa é que, com tantas mudanças referentes à obtenção do pescado, os conflitos socioeconômicos, socioambientais e socioculturais estão cada vez mais presentes nas comunidades que desenvolvem a pesca artesanal. Bail e Branco (apud CABRAL, 1997) atentam que, no Brasil, a pesca artesanal tem recebido ao longo dos tempos poucos incentivos governamentais. Embora seja uma atividade importante na medida em que abastece local e regionalmente os mercados de pescados e é a atividade principal para uma expressiva parcela da população litorânea brasileira.

É importante relatar que a região foco deste estudo apresenta aumento significativo de pessoas que se deslocam para esse local no período do verão. E isso acarreta problemas relacionados à especulação imobiliária, ao abastecimento de água e à falta de um sistema de tratamento do esgoto, vindo a somar aos já existentes problemas referentes à pesca.

A comunidade visitada encontra-se distribuída em dois locais na área do Farol de Santa Marta: a Prainha e a Praia do Cardoso. A Prainha é a praia principal, onde fica concentrada a parte do comércio e as melhores estruturas e, no local, pode-se encontrar uma pequena enseada na qual não é raro ver alguns golfinhos. Nesse local, a água é própria para banho nos meses de menor fluxo de pessoas; em alta temporada, a praia recebe grande quantidade de esgoto, proveniente das residências instaladas na área que não apresentam saneamento adequado, tornando, dessa forma, as águas impróprias para banho no período de verão. No segundo local, a Praia do Cardoso, concentra-se o maior número de pescadores e serve de base para os galpões que guardam as embarcações e equipamentos de pesca. No verão, também é conhecida por receber um público bem jovem de surfistas por conta das grandes ondas. Tem menos estrutura que sua vizinha Prainha.

A metodologia utilizada na aula prática foi a observação participante direta, também denominada observação participante por distanciamento (ALBUQUERQUE; LUCENA; 
ALENCAR, 2010), que se caracteriza por usar fontes diversas para assegurar uma coleta compreensível de informações da comunidade a ser observada. A comunidade tem papel fundamental, pois é a fonte de informações e faz parte de uma realidade social. Consequentemente, a solução de um problema deve ser proposta através de um processo de construção coletiva.

O texto está divido em três partes, todas diretamente relacionadas à organização e desenvolvimento da região. A primeira teve o objetivo de caracterizar a comunidade em seu processo histórico de origem, a segunda traz a discussão da pesca artesanal e seus conflitos socioeconômicos e, por fim, a terceira aborda os principais conflitos e fatores que afetam a estabilidade dos sistemas pesqueiros.

\section{DESENVOLVIMENTO}

\subsection{CARACTERIZAÇÕES DA COMUNIDADE}

A história da região abarca em torno de5.000anos, observados pela presença dos maiores sítios arqueológicos do tipo Sambaqui do mundo.

$\mathrm{Na}$ região, foram encontrados resquícios de outras populações pré-históricas de caçadores e coletores que moldaram todo o contexto físico e natural da região. Por volta de 1000 d.C, chegaram os ceramistas Jê, e trezentos anos depois, os Tupi-Guarani, que habitavam a região e tinham como base a pesca, caça e coleta de alimentos, confecção de artefatos líticos e cerâmicos (CLAUDINO; FARIAS, 2009).

O Cabo de Santa Marta recebeu esse nome no ano de1502, quando, segundo o historiador Lucas Boiteux, o comandante André Gonçalves teria atracado à região em 23 de fevereiro, dia que se festeja Santa Marta de acordo com o calendário romano.

No ano de 1748, aproximadamente 40 casais imigrantes açorianos com alguns mantimentos, vestes e utensílios, num total de 215 pessoas, foram enviados para povoar a região entre Passagem da Barra, Farol de Santa Marta, Garopaba do Sul e Campos Verdes.

É nesse local, conhecido como a esquina do Atlântico, que foi solicitada ao Ministério da Marinha a construção de um farol para evitar os inúmeros naufrágios. O farol de Santa Marta é o maior das Américas e sua construção se deu no ano de 1891, pela companhia francesa Barbier.

A primeira família a chegar à região do Cabo de Santa Marta teria sido a do pescador Eliziário Patrício, em 1909, de acordo com o registro obtido por Martins (1997). Este transcreve em seu livro um trecho de entrevista concedido pelo pescador à revista Vida Doméstico, em 1947:

Aqui chegamos em primeiro de maio de 1909. Tudo isso era mato. Não morava aqui mais ninguém, a não ser os faroleiros. Quando chegamos, por não termos onde nos abrigar fizemos uma barraca com a vela de nossa canoa, e aí moramos por muitos dias, até que fizemos um 
Revista Tecnologia e Ambiente, v. 25, 2019, Criciúma, Santa Catarina/SC ISSN Eletrônico 2358-9426 e ISSN Impresso 1413-8131

rancho de palhas. Hoje isto está como o senhor vê, todo povoado. Não sei se fiz bem ou mal (apud MARTINS, 1997, p. 9).

Figura 1 - Prainha nas décadas de 1960 e 1970.

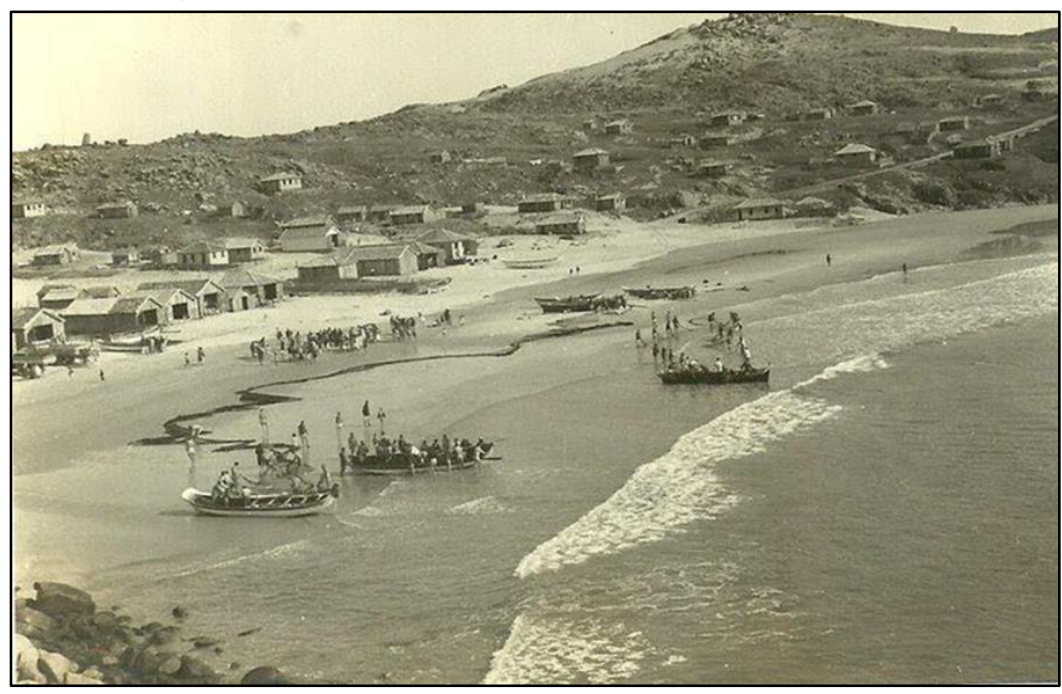

Fonte: http://postsabeiramar.blogspot.com/2013/06/o-cabo-da-santa-marta-e-o-maior-farol.html

Figura 2 - Prainha nas décadas de 1960 e 1970.

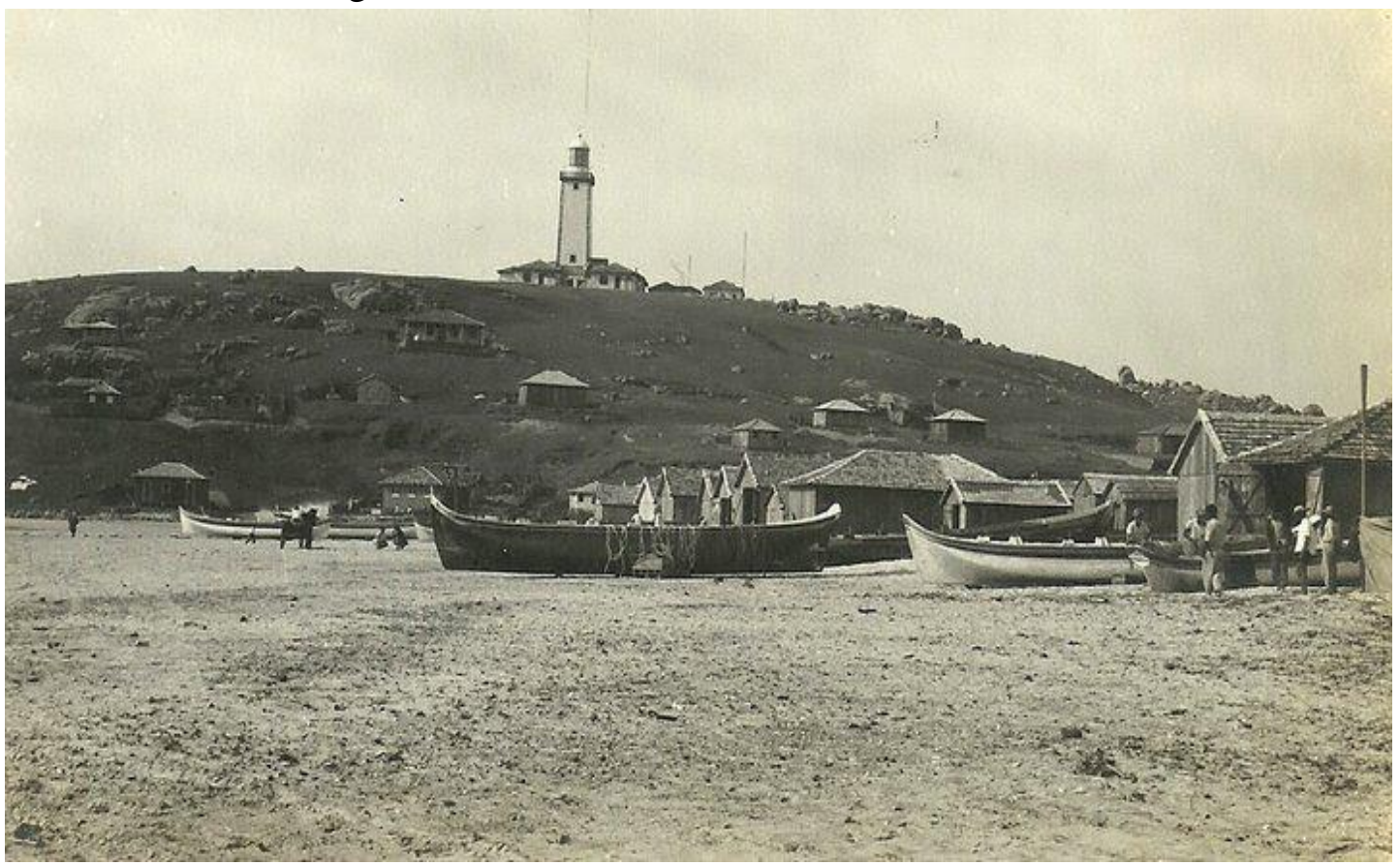

Fonte: http://postsabeiramar.blogspot.com/2013/06/o-cabo-da-santa-marta-e-o-maior-farol.html

A Prainha é a praia principal, onde ficam concentradas a maior parte do comércio e a melhor estrutura para o turismo. Na época de veraneio, devido ao aumento da quantidade de pessoas, suas águas recebem maior quantidade de esgoto e, pela falta de infraestrutura e saneamento, pode tornarse imprópria para o banho. 
Figura 3 - Vista frontal da Prainha.

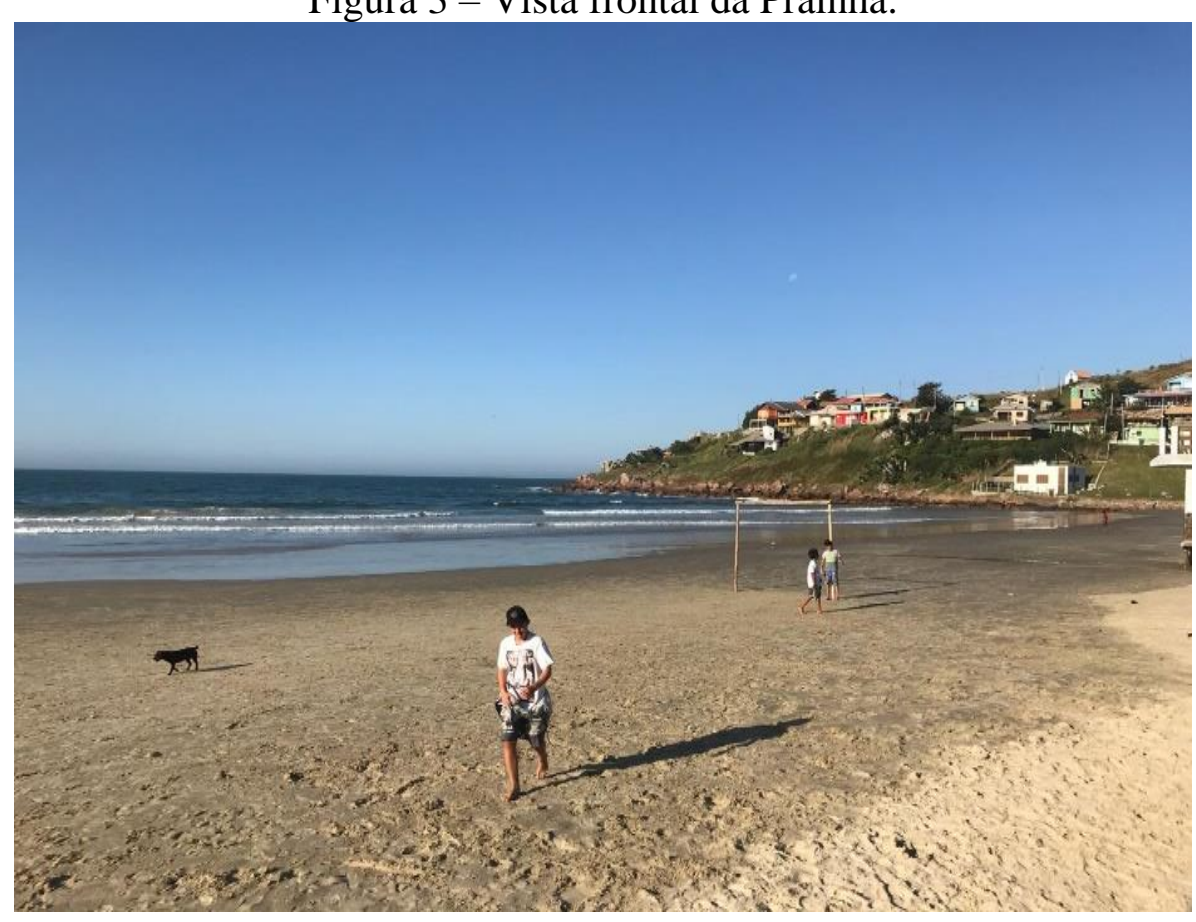

Fonte: Acervo pessoal

A Praia do Cardoso é a utilizada pelos pescadores para adentrar no mar e guardar suas embarcações e equipamentos de pesca em cabanas apropriadas. Porém, no verão, é muito procurada para a prática do surfe por conta de suas ondas.

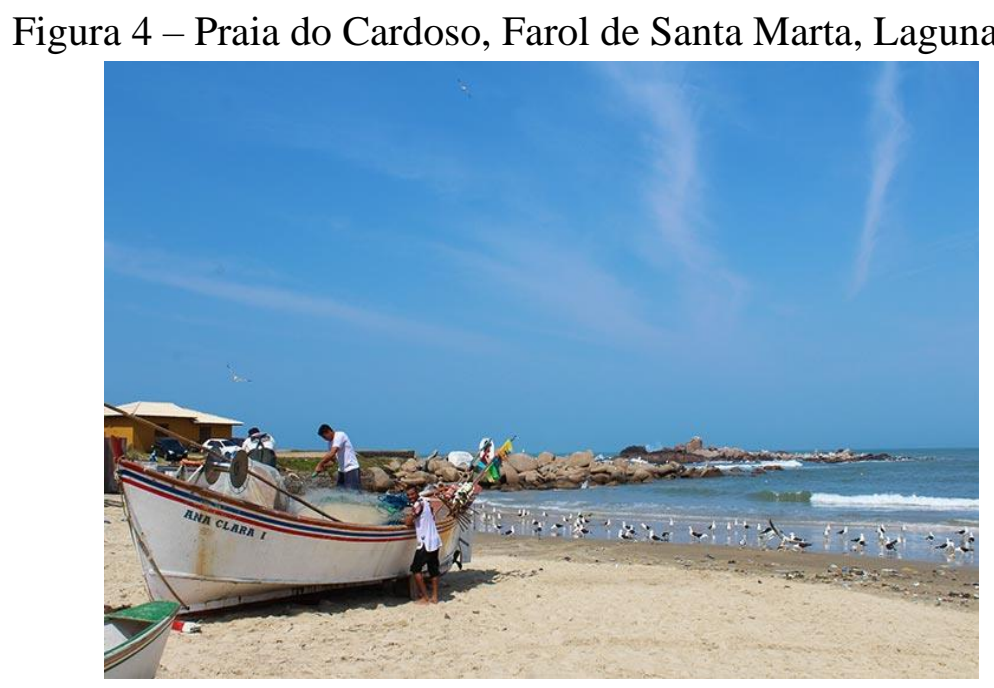

Fonte: Acervo pessoal

A temporada de pesca da tainha é muito importante para a região e acontece entre os meses de maio e julho. Nesse período, o surfe costuma ser proibido em certos dias para não prejudicar a pesca. 
Na região, há cerca de duzentas famílias de pescadores e $80 \%$ vivem da pesca, tendo as atividades relacionadas ao turismo, destacando-se o do tipo comunitário, como complementar. Seus entornos sofrem grande pressão imobiliária e, devido à ocupação desordenada, principalmente pelas residências secundárias, o abastecimento de água é comprometido.

Na Prainha, se encontra a Associação Rasga Mar na Defesa da Natureza (ARDN), a qual, nas palavras de seu estatuto:

[...] é uma entidade cívico-cultural, ONG (Organização Não governamental), de direito privado, sem fins lucrativos e não distribui resultados, dividendos, bonificações, participações ou parcela do seu patrimônio sob nenhuma forma ou pretexto, sem fins políticopartidários ou religiosos, de caráter educativo e de promoção social, com prazo de duração indeterminado e se regerá pelo presente estatuto e legislação em vigor.

A primeira proposta era ser uma grife especializada no vestuário de surfistas, adeptos e jovens em geral, de propriedade de João Batista de Andrade, nativo do Farol de Santa Marta, filho de pescador João Gancheiro e de dona Fausta Andrade.

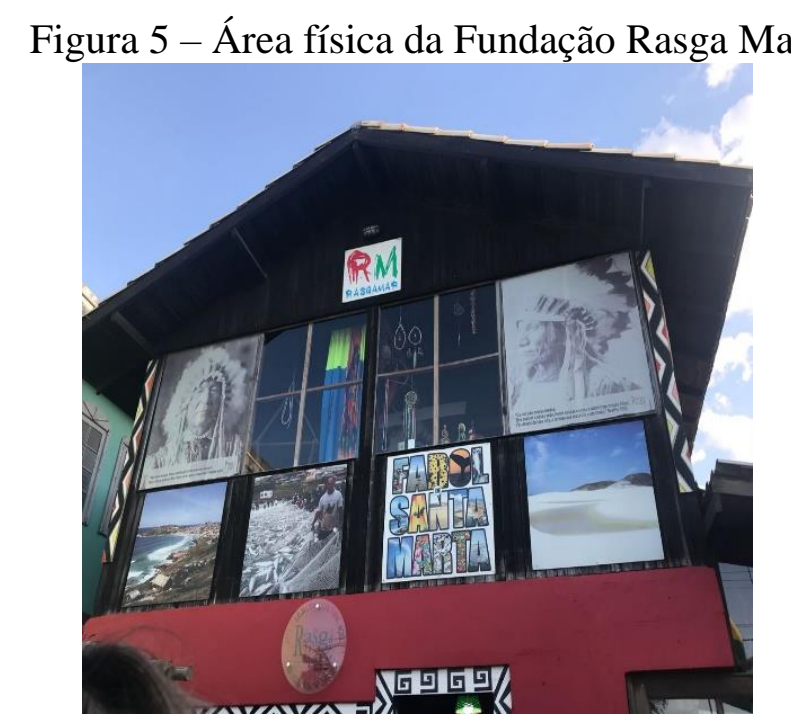

Fonte: Acervo pessoal

Nas palavras do membro fundador da ARDN:

Nossa geração é responsável por preservar o meio ambiente. A preocupação ecológica começou nos anos 1980, coisa que absolutamente não existia quando meus pais eram jovens. Nem se falava em meio ambiente aqui, porque ele não era afetado significativamente. Mas isso está bem presente e devemos tomar algumas atitudes (BATISTA, mar. 1997).

A comunidade do Farol de Santa Marta se diferencia das outras comunidades pesqueiras, pois é a única que não possui atividades agrícolas em paralelo à de pesca. Esse fato se dá pela região não apresentar um solo próprio para cultivo. 
Revista Tecnologia e Ambiente, v. 25, 2019, Criciúma, Santa Catarina/SC ISSN Eletrônico 2358-9426 e ISSN Impresso 1413-8131

\subsection{A CARACTERIZAÇÃO DA PESCA ARTESANAL E SEUS CONFLITOS} SOCIOECONÔMICOS NA REGIÃO DO FAROL DE SANTA MARTA

O Farol de Santa Marta se encontra afastado do núcleo urbano do município de Laguna, separado geograficamente por um complexo constituído de uma entrada de barra de mar, formando uma espécie de ilha, na qual localizam-se também as comunidades da Passagem da Barra, da Cigana e mais outras pequenas vilas (AUTOR, ano).

Figura 7 - Farol de Santa Marta no município de Laguna, estado de Santa Catarina.

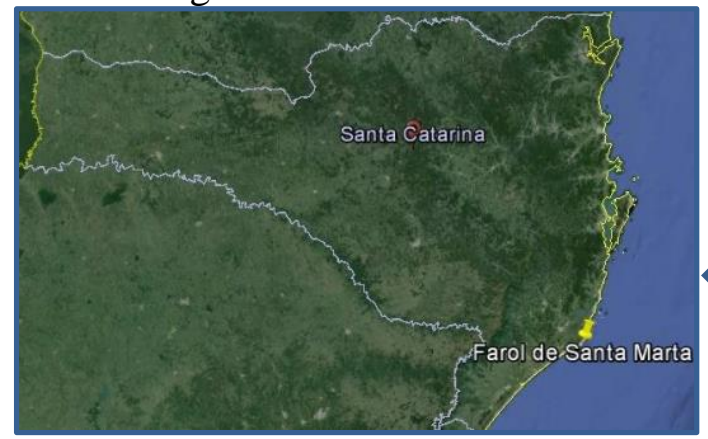

Fonte: Google Earth, 2018.

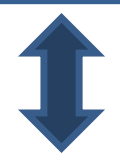

Figuras 8 e 9 - Farol de Santa Marta

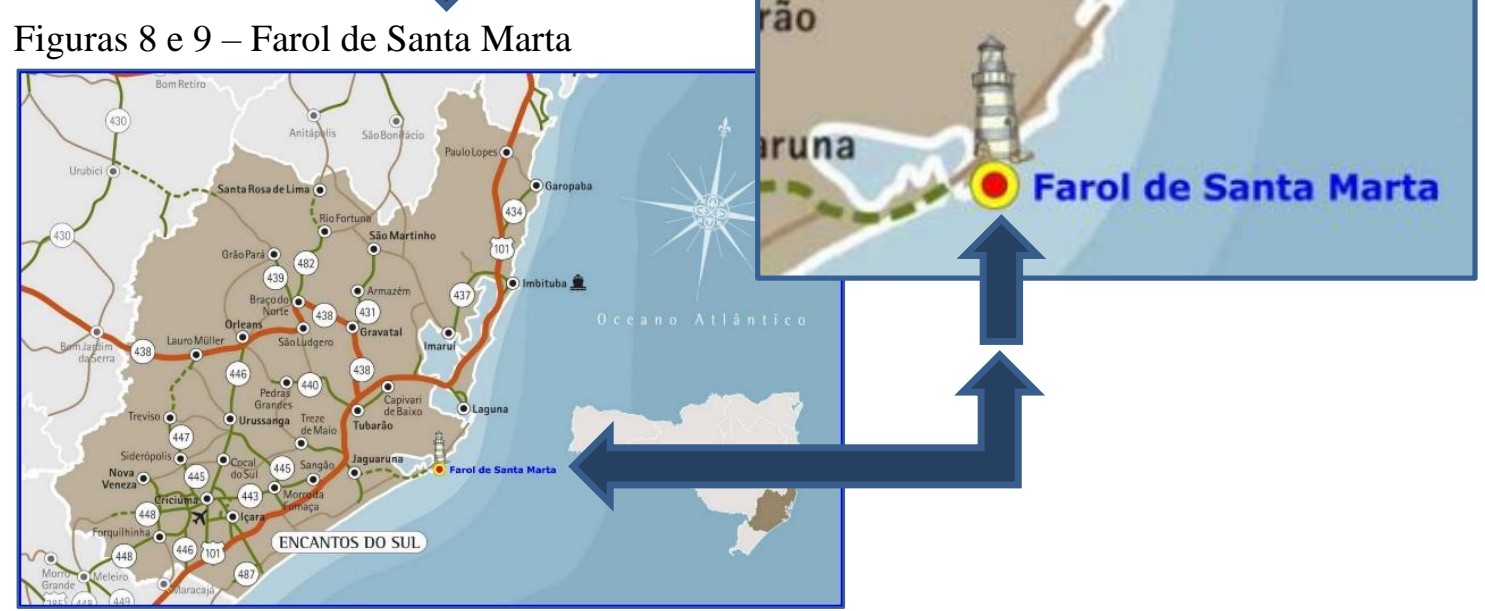

Fonte: https://www.google.com.br/search?rlz=1C1CHZL_pt

A primeira família a chegar à região do Cabo de Santa Marta foi a de Eliziário Patrício, em 1909. Na época, habitavam na região apenas os homens que trabalhavam nas instalações do farol, que deu origem ao nome da comunidade do Farol de Santa Marta.

Muitos deles que haviam trabalhado na construção do farol se fixaram em definitivo para a localidade com objetivo de se dedicarem à pesca artesanal, atividade a partir da qual organizou-se a vila de moradores (MARTINS, 1997, p. 35).

A pesca, como exploração dos recursos marinhos no litoral de Santa Catarina, exerce papel relevante no contexto socioeconômico. Essa atividade foi uma entre os legados da cultura açoriana que contribuiu de maneira expressiva para o desenvolvimento da pesca artesanal e industrial no litoral 
do estado de Santa Catarina (CAPELLESSO, 2010). Entretanto, a pesca artesanal na região de Laguna/SC, mais precisamente no Farol de Santa Marta, vem sendo severamente afetada em decorrência da redução do pescado, face os problemas ambientais desencadeados na bacia hidrográfica do Rio Tubarão e o aumento da pesca industrial (CAPELLESSO, 2010).

Para Martins (1997), pescadores artesanais são aqueles que trabalham com barcos cuja capacidade atingem até 20 toneladas.

Os barcos utilizados para pesca podem ser as traineiras, o emalhe anilhado, as baleeiras e os botes. As traineiras são barcos utilizados para pesca industrial e possuem capacidade elevada de passageiros e de carga de pesca. Também são equipadas com tecnologia avançada, o que contribui fortemente para o sucesso da pesca, devido à localização facilitada de cardumes e à fácil identificação de tempestades em alto-mar e banco de areia que encalham os barcos, entre outros fatores geradores de prejuízo à pesca. As traineiras também apresentam vantagem com relação aos barcos de pesca artesanal devido às acomodações oportunizadas aos pescadores e à possibilidade de permanecer em alto-mar durante horas ou dias. As redes utilizadas para pesca possuem malha fina, o que contribui para que os barcos fiquem abarrotados rapidamente.

Figuras 10 e 11 - Traineiras - barcos de pesca industrial.
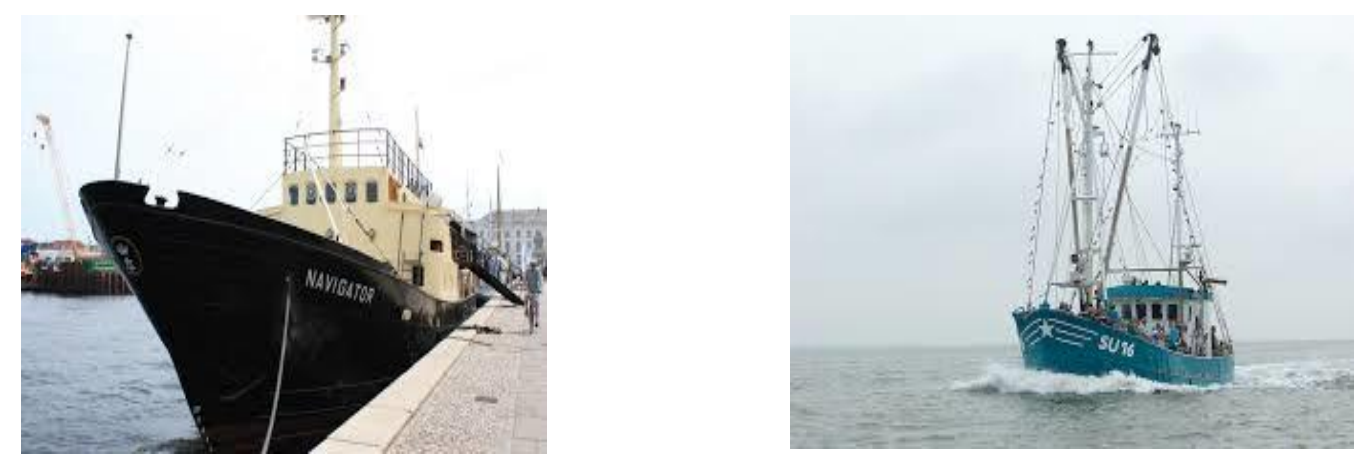

Fonte: https://www.google.com.br/url?sa=i\&source=images\&cd

Segundo os pescadores da comunidade do Farol, na pesca industrial " [...] se pega de tudo... peixe grande, peixe pequeno, peixe de época e até mesmo fora de época..."Os pescadores da comunidade do Farol de Santa Marta, em sua maioria, utilizam os botes para pescaria.

Figuras 12 e 13 - Botes - barcos de pesca artesanal.
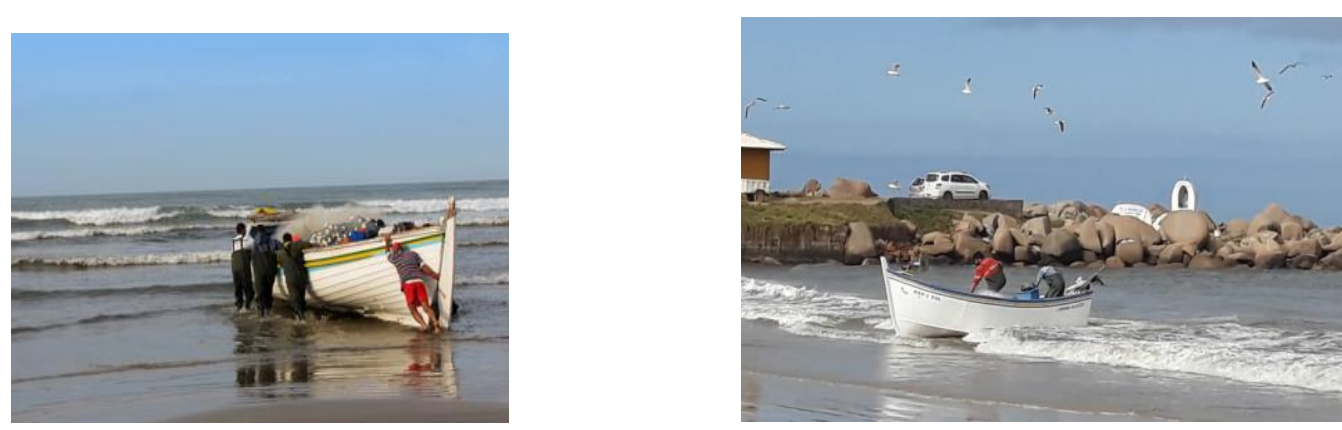

Fonte: https://www.google.com.br/url?sa=i\&source=images\&cd 
Somente uma equipe de pescadores, coordenada pelo bisneto do senhor Eliziário Patrício, utiliza a baleeira com o objetivo de manter a tradição da família. Entretanto, a capacidade em toneladas de ambos, botes e baleeiras, é a mesma.

Figura 14 - Baleeira - barco de pesca artesanal.

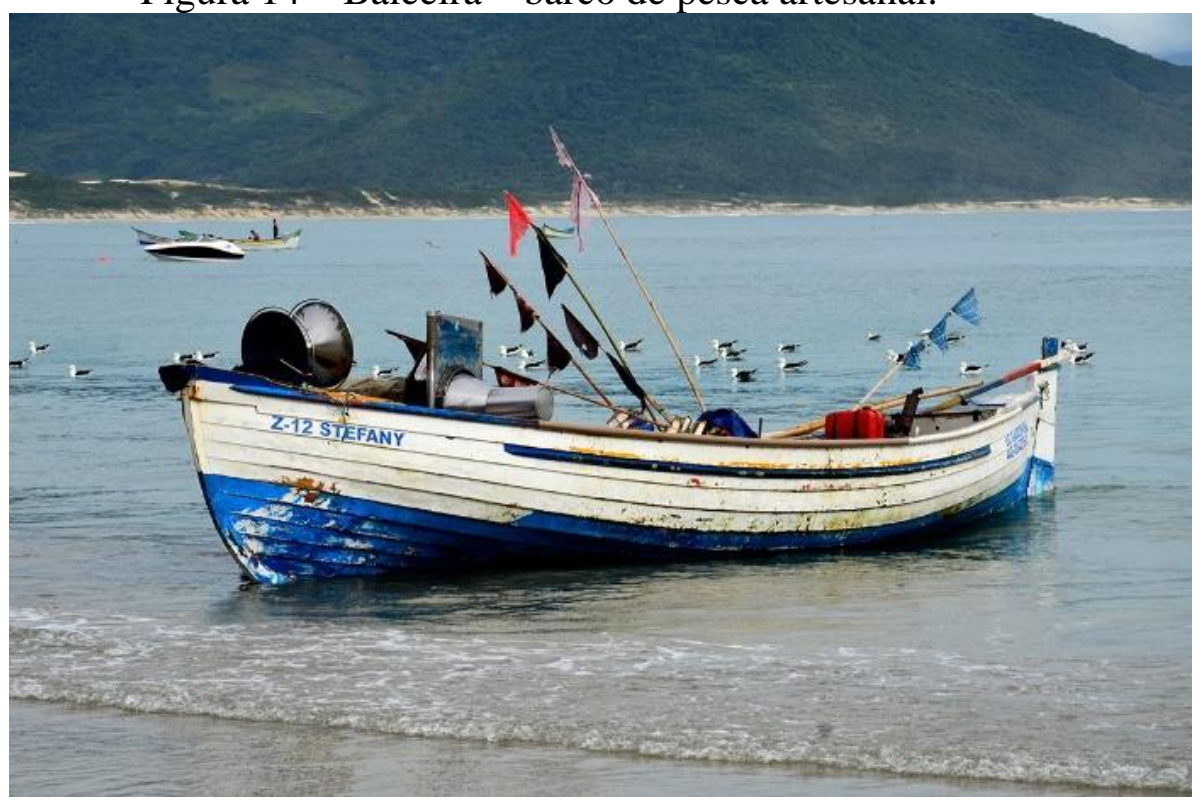

Fonte: https://www.google.com.br/url?sa=i\&source=images\&cd

As redes de pesca são confeccionadas pelos pescadores e, para cada tipo de peixe, existe um tipo de rede com as medidas das malhas adequadas ao peixe da época.

Figura 15 e 16 - Redes confeccionadas pelos pescadores.
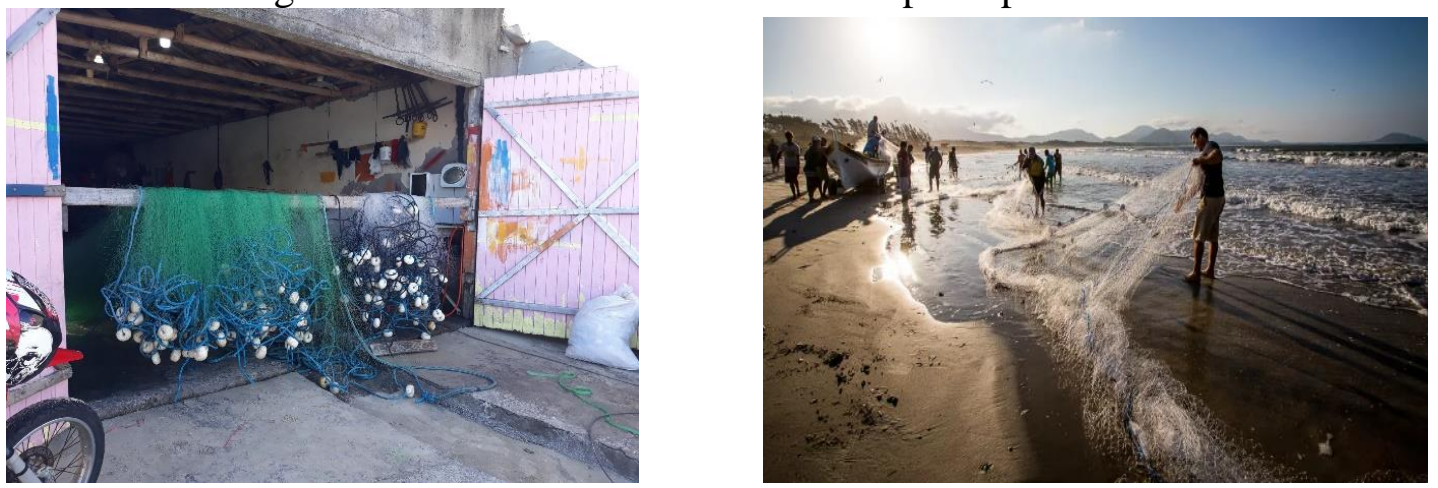

Fonte: Acervo pessoal.

De acordo com Capellesso (2010), a pesca é realizada de acordo com portarias publicadas pelo governo estadual e federal. Tais portarias visam a contribuir com vantagens para a pesca artesanal, contudo, a realidade que se apresenta demonstra uma disparidade entre elas (artesanal e industrial). Uma embarcação que possui capacidade para 100 toneladas é substituída por cinco embarcações com capacidade de 20 toneladas cada. Dessa forma, a pesca industrial pode desfrutar 
dos direitos reservados pela pesca artesanal, bem como dos seus direitos de embarcações de grande porte, sem correr o risco de infringir a lei.

Nas portarias, também são estabelecidas cotas limites de pesca e períodos permitidos de acordo com as espécies de peixes. As cotas giram em torno de 3.147 toneladas por espécie de peixe e o período de pesca varia. Para a tainha, a temporada para a pesca artesanal se inicia com cerca de um mês de antecedência, ou seja, 15 de maio, e vai até 31 de junho.

Para os pescadores da comunidade em foco, as maiores desvantagens se traduzem nas seguintes pontos, identificados por eles como "realidade esmagadora":

Pesca industrial em 1 semana captura a sua cota.

Barcos de pesca industrial possibilitam que pescadores praticamente morem no mar. Equipamentos tecnológicos que facilitam a captura dos peixes (localização de cardumes). Equipamentos tecnológicos que indicam situações favoráveis de pesca (meteorologia).

Esforço físico muito menor... eles até dormem...

Os barcos suportam maiores profundidades - "entram mais no mar".

Redes com malhas menores - "pegam tudo...".

Desrespeitam as limitações concedidas para pesca.

Emalhe anilhado prejudica no lançar a rede ao mar

[...] nossas redes ficam presas nos ferros deles... é melhor nem colocar no mar, é prejuízo certo... a gente vem embora sem nada mesmo...

Saímos às $2 \mathrm{~h}$ da madrugada e retornamos muitas vezes a tardinha (tentativa exaustiva de capturas de peixes) - comum acontecer.

Pesca industrial entra nos limites da pesca artesanal de praia à noite (até $2 h$ ) e acaba por capturar os peixes "[...] não sobra nada pra nós...”;

[...] eles burlam a quantidade de peixes pescados... estão no mar... a gente tem que voltar pra praia e a fiscalização fica em cima... nunca se sabe quando eles vem aqui...

[...] semana passada colocaram 100 toneladas fora, a fiscalização foi pro mar (por milagre) e tinham muito além da cota pescado...mas a gente ficou sem peixe igual.

[...] estamos sem pescar desde domingo, agora que o tempo melhorou...os barracos dali tão até fechados, não arriscaram entrar. A gente arriscou, mas veio quase nada...

O que nos ajuda é o seguro... a gente faz pra mulher e pra nós daí dá 8 salários em 4 meses... a gente economiza pra não faltar...

[...] quem se organiza tem até umas casinhas pra se virar e conseguir viver de outra coisa...

[...] muitos incentivam os filhos a estudar e deixar essa vida...

Muitas vezes, em um mês a gente entra dez vezes e eles podem estar lá todos os dias...

[...] eles têm mais dinheiro pra manutenção e pra bancar prejuízo... a gente se não se cuidar nunca mais se recupera... mas nunca ninguém passou fome, a gente se ajuda...

Nós mesmos que fizemos as nossas redes, é uma malha pra cada tipo de peixe... tem malha que pega mais de um tipo... eles têm rede que pega tudo que não sobra nada...

[...] nossa associação não é legitimada... nunca vamos conseguir nada...

E finalizam as falas com o seguinte:

[...] o problema não é a pesca industrial; já ganhei muito minha vida na pesca industrial... são todos pai de família que nem nós...o problema é o respeito que ninguém tem...

\section{DISCUSSÃO: PRINCIPAIS CONFLITOS E FATORES QUE AFETAM A ESTABILIDADE DOS SISTEMAS PESQUEIROS}

A comunidade do Farol de Santa Marta teve sua origem ligada à atividade pesqueira. 
Há muito tempo, a pesca artesanal é uma atividade que tem como responsabilidade ser uma forma de sustento de uma grande parcela da população da comunidade do Farol de Santa Marta. Contudo, essa prática cultural vem enfrentando vários contrapostos atualmente, estando entre eles a ausência de fiscalização, o que propicia a sobrepesca e provoca a diminuição no número de indivíduos e espécies aquáticas. Tudo está interligado, desencadeando uma série de fatores que prejudicam a atividade dessas comunidades litorâneas, além de causar impactos negativos ao meio ambiente. Para esses quesitos, pode-se citar também a influência da poluição sobre essas atividades. Todos esses fatores juntos trazem para essa cultura de muitos anos um risco para sua preservação e sobrevivência (DIEGUES, 1999).

Quando falamos sobre pesca artesanal, é evidente a forte ligação dessa atividade com o ambiente, a natureza. Existe uma intensidade nessa relação, na qual não é possível manter um controle humano sobre esses recursos naturais. E, a partir desse ponto, faz-se necessária uma adaptação dos pescadores, para que se construa uma relação com o ambiente de trabalho, visto que torna importante um determinado respeito e conhecimento sobre as condições do meio (DIEGUES, 1999). E aí pode ser observado um forte fator na estabilidade dos sistemas pesqueiros artesanais, que seria a pesca industrial. Quando trabalhamos com a pesca artesanal, existem limitações, tais como condições das marés, redes utilizadas, clima e até mesmo dos cardumes. Logo, para a pesca industrial, esses fatores não a afetam, ou afetam de maneira muito menos agressiva, quando comparados com a pesca artesanal e cultural (CAPELLESSO, 2010).

A atividade pesqueira industrial é intensa, diminuindo significativamente o número de cardumes e prejudicando na desova de novos indivíduos, para a próxima época de pesca das comunidades pesqueiras (CAPELLESSO, 2010). Outro fator que afeta os pescadores artesanais é a falta de fiscalização em alto-mar. Ocorrendo pela pesca industrial, que tem seu espaço definido por lei, mais adentro do oceano, um número maior que o permitido de pescado, diminuindo ou acabando com vários cardumes, antes de chegarem à área de pesca das comunidades (CAPELLESSO, 2010). Esse tipo de atividade, que faz a retirada excessiva dos recursos naturais, além de afetar a pesca artesanal, afeta também os ecossistemas, devido ao desrespeito ao tempo de reprodução das espécies, tirando do meio mais do que ele mesmo consegue repor novamente (DIEGUES, 1999).

Além desse problema, ocorre também, por falta de uma melhor fiscalização, a utilização de redes não permitidas, com as suas malhas menores do que deveriam por lei, deixando claro que a sobrepesca industrial é o fator que mais causa impactos negativos sobre a pesca artesanal.

Onde predomina a pesca com canoa de arrasto da tainha, os pescadores atribuem a diminuição das capturas à sobrepesca industrial, à falta desse pescado na costa e à maior agitação do oceano nos últimos anos. Dessa forma, as capturas têm diminuído e ocasionado a desativação de várias embarcações. Entre os camaradas e donos desse tipo de embarcação 
(normalmente de propriedade coletiva), é comum a argumentação de que a safra da tainha tem sido somente suficiente para atender o consumo familiar, peixe que apreciam muito. Em raros casos, ocorrem "lanços" com maiores quantidades, que permitem a venda. Assim, alguns afirmam que a manutenção dessa pescaria tem se dado mais pela tradição do que pelo seu retorno econômico (CAPELLESSO, 2010, p. 34).

\section{CONSIDERAÇÕES FINAIS}

Pelo exposto, percebe-se, a partir desses problemas, que não apenas a natureza é afetada diretamente, mas também os pescadores artesanais, que vêm enfrentando maiores dificuldades para garantir o seu sustento. Como consequência desse cenário, muitos dos pescadores acabam apelando para o aluguel de suas casas na comunidade, engajando-se e dependendo de outros ramos, como o turismo em época de temporada de veraneio.

\section{REFERÊNCIAS}

ALBUQUERQUE, U.P.; LUCENA, R.F.P.; ALENCAR, N.L. 2010. Métodos e técnicas para coleta de dados etnobiológicos. In: Albuquerque, U.P.; Lucena, R.F.P.; Cunha, L.V.F.C. (Ed.), Métodos e técnicas na pesquisa etnobiológica e etnoecológica. Recife, NUPEEA, p. 39-64. 2010.

CAPELLESSO, A. J. Os sistemas de financiamento na pesca artesanal: um estudo de caso no litoral centro-sul catarinense. 2010. 164 f. Dissertação (Mestrado em Agroecossistemas) - CCA, UFSC, Florianópolis.

CLAUDINO, D. C.; FARIAS, D. S. E. Arqueologia e preservação: Sambaqui Morro do Peralta. Florianópolis: Samec, 2009.

DIEGUES, A. C. S. A. A sócio-antropologia das comunidades de pescadores marítimos no Brasil. Revista Etnográfica, v. 3, n. 2, p. 361-375, 1999.

MARTINS, C. Farol de Santa Marta - A esquina do Atlântico. Garapuvu, 1997. 